This item was submitted to Loughborough's Research Repository by the author.

Items in Figshare are protected by copyright, with all rights reserved, unless otherwise indicated.

\title{
A new model based on adiabatic flame temperature for evaluation of the upper flammable limit of alkane-air-CO2 mixtures
}

PLEASE CITE THE PUBLISHED VERSION

https://doi.org/10.1016/j.jhazmat.2017.10.030

\section{PUBLISHER}

(C) Elsevier

\section{VERSION}

AM (Accepted Manuscript)

\section{PUBLISHER STATEMENT}

This work is made available according to the conditions of the Creative Commons Attribution-NonCommercialNoDerivatives 4.0 International (CC BY-NC-ND 4.0) licence. Full details of this licence are available at: https://creativecommons.org/licenses/by-nc-nd/4.0/

\section{LICENCE}

CC BY-NC-ND 4.0

\section{REPOSITORY RECORD}

Wu, Mingqiang, Gequn Shu, Rui Chen, Hua Tian, Xueying Wang, and Yue Wang. 2018. "A New Model Based on Adiabatic Flame Temperature for Evaluation of the Upper Flammable Limit of Alkane-air-co2 Mixtures". figshare. https://hdl.handle.net/2134/28375. 


\title{
A new model based on adiabatic flame temperature for evaluation of the upper flammable limit of alkane-air- $\mathrm{CO}_{2}$ mixtures
}

Mingqiang Wu, Gequn Shu, Rui Chen, Hua Tian*, Xueying Wang, Yue Wang

State Key Laboratory of Engines, Tianjin University, People's Republic of China

Accepted for publication by Journal of Hazardous Materials (October 2017)

\section{Highlights}

- A new model based on adiabatic flame temperature has been proposed.

- A linear relationship exists between dilution ratio and calculated adiabatic flame temperature.

- The flammable zones of $\mathrm{n}$-butane- $\mathrm{CO}_{2}$ and isopentane- $\mathrm{CO}_{2}$ were measured to test effectiveness of the VAFT model.

- The average relative differences are less than $3.51 \%$ at upper flammability limit for VAFT model.

\begin{abstract}
For security issue of alkane used in Organic Rankine Cycle, a new model to evaluate the upper flammability limits for mixtures of alkanes, carbon dioxide and air has been proposed in present study. The linear relationship was found at upper flammability limits between molar fraction of diluent in alkane- $\mathrm{CO}_{2}$ mixture and calculated adiabatic flame temperature. The prediction ability of the variable calculated adiabatic flame temperature model that incorporated the linear relationship above is greatly better than the models that adopted the fixed calculated adiabatic flame temperature at upper flammability limit. The average relative differences between results predicted by the new model and observed values are less than $3.51 \%$ for upper flammability limit evaluation. In order to enhance persuasion of the new model, the observed values of $n$-butane- $\mathrm{CO}_{2}$ and isopentane- $\mathrm{CO}_{2}$ mixtures measured in this study were used to confirm the validity of the new model. The predicted results indicated that the new model possesses the capacity of practical application and can adequately provide safe non-flammable ranges for alkanes diluted with carbon dioxide.
\end{abstract}

\section{Keywords}

Flammability limits; Dilution ratio; Theoretical models; Variable calculation adiabatic flame temperature; Experimental method

\section{Nomenclature}

Abbreviations

CAFT Calculated adiabatic flame temperature

FAFT Fixed calculated adiabatic flame temperature 
VAFT Variable calculated adiabatic flame temperature

LOC Limiting oxygen concentration

LFL Lower flammability limit

UFL Upper flammability limit

RD Relative difference

\section{Symbols}

$U$ the molar fraction of alkane in the alkane-air-diluent mixture at UFL

$Y \quad$ the molar fraction of diluent in alkane-diluent mixture

$H_{0} \quad$ Enthalpy at the initial temperature

$H_{a d} \quad$ Enthalpy at the calculated adiabatic flame temperature

$\Delta H_{c}{ }^{*} \quad$ Reaction heat at upper flammability limit

$\Delta H_{c} \quad$ Heat of the combustion

$U_{1} \quad$ Lowest volume fraction does not support flame propagation

$U_{2} \quad$ Highest volume fraction supports flame propagates

$\alpha \quad$ The quantity of combustion product at UFL

\section{Introduction}

Propane and isobutane show good characters as working medium in medium-high temperature Organic Rankine Cycle $[\mathbf{1 , 2}]$ which is an appropriate technology for waste heat recovery like engine and industry. However, flammability of those is a mainly big limitation for using in its practical application. Among flammability characteristics, flammability for alkanes is an important one which defines the range of fuel concentration for flame propagation to occur. Inerting is the process of adding an inert gas to a combustible mixture to reduce the concentration of oxygen below the limiting oxygen concentration (LOC) for the purpose of lowering the likelihood of explosion [3]. Thus, inerting is frequently involved to reduce the possibility of flammability lest the high temperature flammable working medium leaking from Organic Rankine Cycle explodes in the surrounding environment. Using carbon dioxide as an inert gas, Ref. [4] revealed that mixture of carbon dioxide and alkane had a better performance in cycle efficiency than alkane in Organic Rankine Cycle owing to a large temperature glide for alkane- $\mathrm{CO}_{2}$ mixture.

The prediction of flammability limits for alkane- $\mathrm{CO}_{2}$ mixture plays some positive significance in practical application of Organic Rankine Cycle. Theoretical approaches can better interpret the effect of inert gas on flammability limits of fuel and easily estimate the flammable ozone than experimental methods. Thus, different methods have been proposed in quantity to estimate the flammability limits for mixture of fuel and inert gas in literatures such as the modified Le Chatelier equation [5] and the thermal theory methods [6]. However, the modified Le Chatelier equations are highly dependent on the experimental data so that the predicted results may be inaccurate for 
compounds have not been measured. The thermal theory methods that quantify the heating and quenching potentials of each element of the alkane- $\mathrm{CO}_{2}$ mixture are generally used to predict the flammability zone of the alkane- $\mathrm{CO}_{2}$ mixture. From the perspective of thermal theory, the flammability limits are related to a certain critical energy generation rate or with a certain level of reaction temperature [7]. The flame temperature calculated by assuming no heat loss is known as calculated adiabatic flame temperature (CAFT) [8]. A threshold temperature must be chosen properly to estimate flammability limits by using the CAFT method. Vapor mixtures with its CAFT above this threshold are considered flammable, and vapor mixtures with its CAFT below this threshold are considered nonflammable [9]. Vidal [10] applied a FAFT value to estimate LFL of alkane and got a relatively satisfactory result. Chen [11] developed predictive methods for estimating flammability limits of combustible gas diluted with carbon dioxide using FAFT at both LFL and UFL. The results clearly showed that predicted values of LFL with FAFT accorded with the experimental values, while those of UFL had a large error in comparison with those of LFL. Recently Shu $[\mathbf{1 2 , 1 3 ]}$ proposed flame temperature theory-based models using the FAFT as well for evaluation of the flammable zones of alkane-air- $\mathrm{CO}_{2}$ mixtures. Similar results that large error occurred at UFL could be obtained in that paper. In general, the models adopting the FAFT could exactly predict LFL of alkane-air- $\mathrm{CO}_{2}$ mixtures; however, the same models failed to precisely estimate UFL of alkane-air- $\mathrm{CO}_{2}$ mixtures.

At the same time some attempts have been focused on the VAFT. Hu [14] considered that the differences between the predictions and measurements at UFL were mainly due to the assumption of FAFT in his model. Palucis [15] also pointed out that a FAFT value could be related to the lower flammability limit (LFL), but this was not the case for UFL. The adiabatic flame temperature calculated in Refs. $[\mathbf{1 4 , 1 5}]$ at UFL varied with the addition of the diluent rather than always kept constant. In other words, threshold temperature used for judging flammability limits varied. Therefore, using the FAFT as threshold temperature inevitably resulted in a major error for predicting UFL of alkane-air$\mathrm{CO}_{2}$. This may indicate that the FAFT is no longer fit for predicting UFL. A new procedure for estimation of limiting oxygen concentration (LOC) of fuel-air-nitrogen gaseous mixtures was developed using the VAFT in Razus's paper [16]. The results indicated that the relative difference between predicted values and observed values decrease by more than half comparing with those results obtained by using the FAFT. To the authors' knowledge, there are no models using the VAFT to predict UFL of alkane-air- $\mathrm{CO}_{2}$ mixtures in published literatures.

In conclusion, the existing prediction models have limited ability on precision of prediction at UFL. It is an important task to establish the high precision model to accurately estimate the UFL of alkane-air- $\mathrm{CO}_{2}$ mixtures. Thus, this paper mainly investigates that whether a method using a VAFT that can successfully predicts the change of UFL for flammable mixtures including diluents such as $\mathrm{CO}_{2}$ or $\mathrm{N}_{2}$ exists or not.

As is described above, FAFT was always applied to predict flammability limits of gaseous mixtures of alkane-diluent-air, which may lead to a larger error at UFL in comparison with that of LFL. Thus, the purpose of the present study is to: 1 ) investigate the VAFT; 2 ) propose models based on the VAFT to predict the flammability zones of mixtures composed of alkane, carbon dioxide and air; 3 ) discuss the practical application possibilities and accuracies of the model.

\section{Calculation of VAFT}

The threshold or critical flame temperature used in models is an important fact to determine flammability. As shown Fig. 1, if the threshold temperature, namely CAFT, chosen to determine flammability limits of propane increased, the UFL determined in Fig. 1 should be decrease. The significance meaning of VAFT to determine UFL was revealed distinctly in Fig. 1. 


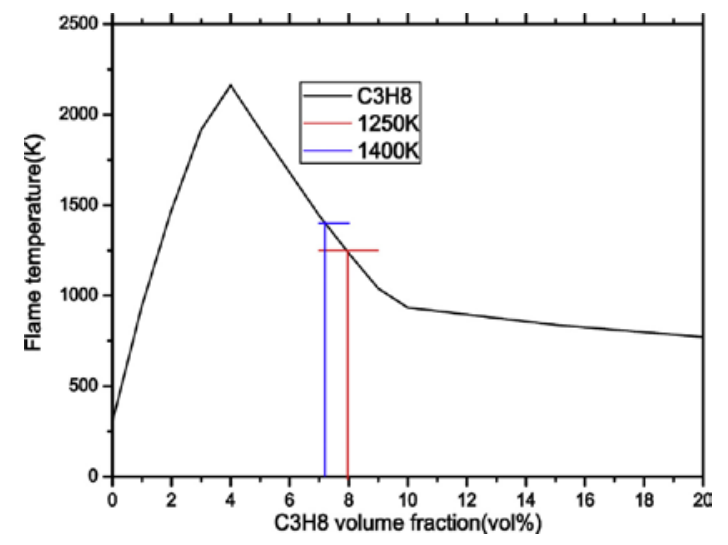

Fig. 1. Comparing the effect of the VAFT on UFL for the mixture of propane- $\mathrm{CO}_{2}$ at $y=0.6$.

Values of CAFT for different pure alkane generally varied from 1000 to $1600 \mathrm{~K}$ according to literature $[\mathbf{1 7}, \mathbf{1 8}]$. In order to precisely get the values of CAFT, the adiabatic flame temperature was calculated by the CHEMKIN software based on chemical equilibrium and minimization of Gibb's free energy for alkane- $\mathrm{CO}_{2}$-air mixture at fixed enthalpy and pressure when values of flammability limits of alkane-carbon dioxide-air mixture are known. Hu [14] also used the CHEMKIN to calculate the adiabatic flame temperature of methane- $\mathrm{CO}_{2}-\mathrm{O}_{2}$ mixture. In this study, the values of flammability limits at $308 \mathrm{~K}$ and $1 \mathrm{~atm}$ for mixtures were taken from Refs. $[\mathbf{1 9 , 2 0 ]}$ published by Kondo. Thus, the values of adiabatic flame temperature at different dilution ratios can be calculated by using the CHEMKIN. As presented in Table 1, the present results have very good coherence to those in Ref. [12], which implies that calculation of adiabatic flame temperature by CHEMKIN is feasible.

Table 1. Comparison between the present CAFT and that in Ref. [12].

\begin{tabular}{lllll}
\hline & Compounds & $\begin{array}{l}\text { CAFT }(\mathrm{K}) \text { in Ref. } \\
{[12]}\end{array}$ & $\begin{array}{l}\text { CAFT }(\mathrm{K}) \text { in } \\
\text { present }\end{array}$ & RD $^{\text {a }}(\%)$ \\
\hline \multirow{2}{*}{ LFL } & Isobutane & 1567 & 1564.8 & 0.14 \\
& Propane & 1497 & 1495.6 & 0.09 \\
\multirow{2}{*}{ UFL } & Isobutane & 1248 & 1250.8 & 0.22 \\
& Propane & 1247 & 1249.1 & 0.17 \\
\hline
\end{tabular}

${ }^{a}$ RD indicates the relative difference between CAFT in Ref. [12] and CAFT in present.

As presented in Table 2, the values of CAFT at LFL for both propane and isobutane are nearly constant in the whole range of LFL, except for the point near FIP; however, the values of CAFT at UFL for both propane and isobutane change remarkably in the whole range of UFL comparing to case at LFL. Variations of CAFT at UFL and LFL mentioned above conform to the situations described in Ref. $[9,15]$. Figures of product distribution with dilution ratio were plotted in order to interpret variations of CAFT at LFL and UFL.

Table 2. Calculation of adiabatic flame temperature for isobutane and propane using program CHEMKIN. 


\begin{tabular}{lllll}
\hline Compounds & $\mathrm{y}^{\mathrm{a}}$ & CAFT at UFL(K) & CAFT at LFL(K) & Notes \\
\hline Isobutane & 0 & 1250.8 & 1564.8 & \\
& 0.15 & 1294.1 & 1556.7 & \\
& 0.30 & 1283.6 & 1560.3 & \\
& 0.45 & 1340.7 & 1562.5 & \\
& 0.60 & 1389 & 1555.4 & FIP \\
& 0.75 & 1379.3 & 1563.9 & \\
Propane & 0.85 & 1402.5 & 1581.4 & \\
& 0.917 & 1496.7 & 1724.8 & \\
& 0.922 & 1724.8 & & \\
& 0 & & 1495.6 & \\
& 0.20 & 1309.5 & 1487.6 & \\
& 0.25 & 1338.3 & 1486.7 & \\
& 0.40 & 1361.7 & 1497.7 & \\
& 0.60 & 1404.3 & 1511.6 & \\
& 0.75 & 1449 & - & \\
& 0.85 & 1448.3 & 1614 & \\
\hline
\end{tabular}

a $\mathrm{y}$ is dilution ratio.

FIP: fuel inertization point in Ref. $[19,20]$.

Figures of concentration of combustion products for propane and isobutane are similar, so taking propane for example to analyze the effect of combustion products on CAFT. From Fig. $\mathbf{2}$ with the exception of region of FIP, equilibrium concentrations of $\mathrm{H}_{2}, \mathrm{H}_{2} \mathrm{O}$ and net concentration (equilibrium concentration of $\mathrm{CO}_{2}$ minus the concentration of $\mathrm{CO}_{2}$ added in mixture as diluent) of $\mathrm{CO}_{2}$ vary at UFL. Fig. 3 and Fig. 5 distinctly indicate that equilibrium concentration of $\mathrm{CO}, \mathrm{H}_{2}, \mathrm{H}_{2} \mathrm{O}$ and net concentration of $\mathrm{CO}_{2}$ keep basically constant at LFL. The different changes of concentration occurred at LFL and UFL may be the reason for FAFT at LFL and VAFT at UFL. Melhem [18] considered that many combustion reactions leading to the formation of carbon dioxide and water had "freeze-out" temperatures on the order of $1400 \mathrm{~K}$. This "freeze-out" limit was most likely related to the minimum temperature required for carbon dioxide to propagate a self-sustaining flame which was around 1400 K. Mashuga [8] pointed out that for any alkane oxidation process $\mathrm{CO}$ was the primary product formed in substantial amounts; the elementary reaction of

$$
\mathrm{CO}+\mathrm{OH} \rightarrow \mathrm{CO} 2+\mathrm{H}
$$

did not begin to occur appreciably until above $1100 \mathrm{~K}$ and was self-sustaining around $1400 \mathrm{~K}$. From the combustion science, the conversion processes from $\mathrm{CO}$ to $\mathrm{CO}_{2}$ and from $\mathrm{H}_{2}$ to $\mathrm{H}_{2} \mathrm{O}$ release the most quantity of heat in combustion. Transformation of combustion products from $\mathrm{CO}$ and $\mathrm{H}_{2}$ to $\mathrm{H}_{2} \mathrm{O}$ and $\mathrm{CO}_{2}$ occurs slowly when dilution ration changes from $0 \%$ to $90 \%$ in Figs. $\mathbf{2}$ and $\mathbf{4}$. Combining the mentioned transformation and Refs $[\mathbf{8 , 1 8}]$, the increase of temperature in Figs. $\mathbf{6}$ and $\mathbf{7}$ is reasonable. Fig. 2 obviously shows a linear relation between the dilution ratio and equilibrium concentration of $\mathrm{H}_{2} \mathrm{O}$ when dilution ratio ranges from 0 to $90 \%$, which may suggest a linear relation between the dilution ratio and CAFT. Figs. 6 and $\mathbf{7}$ validate the linear relation between the dilution ratio and CAFT at mentioned range above with coefficient of determination $\left(R^{2}\right.$-value) of 0.97 and 0.91 for propane and isobutane, respectively. The relation between dilution ratio and CAFT for the methane- $\mathrm{O}_{2}-\mathrm{CO}_{2}$ mixture also is linear at UFL [14]. The calculations suggest that CAFT at UFL really varies with dilution ratio. However, the existing models to predicted flammability limits of alkane- $\mathrm{CO}_{2}$ mixtures always use the FAFT. This may be the cause that leads to large error at UFL. Therefore, the VAFT at UFL will be incorporated as the threshold temperature in modeling procedure. 


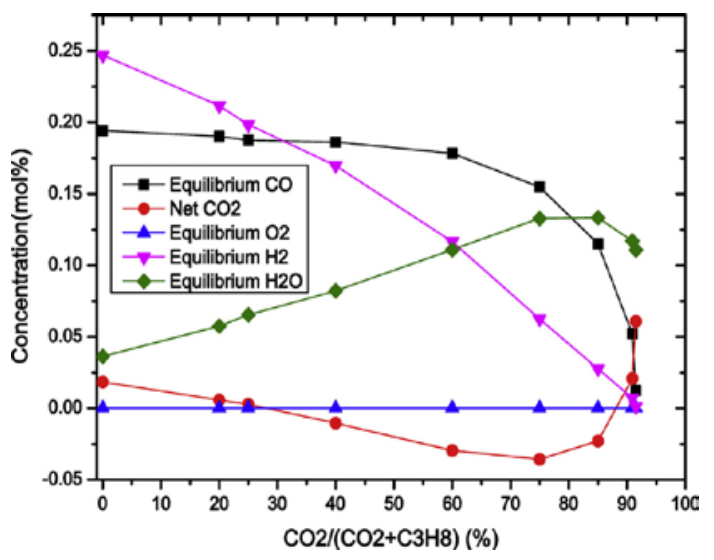

Fig. 2. Concentration of combustion products with different dilution ratio for propane at UFL.

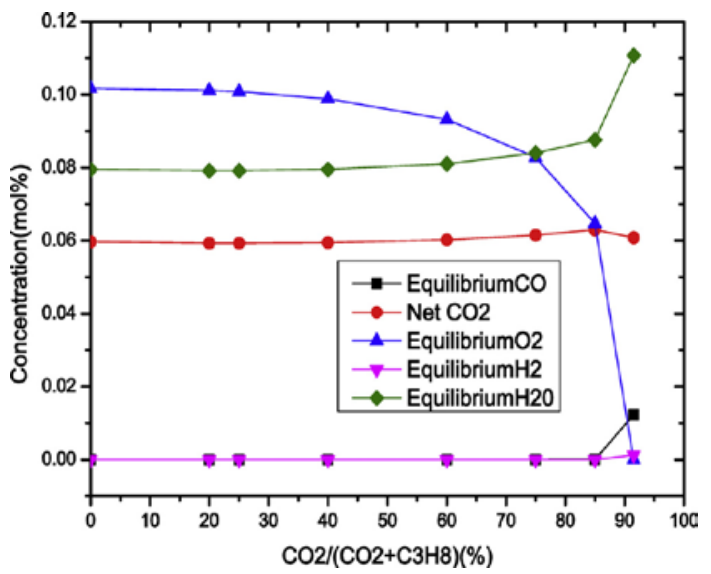

Fig. 3. Concentration of combustion products with different dilution ratio for propane at LFL.

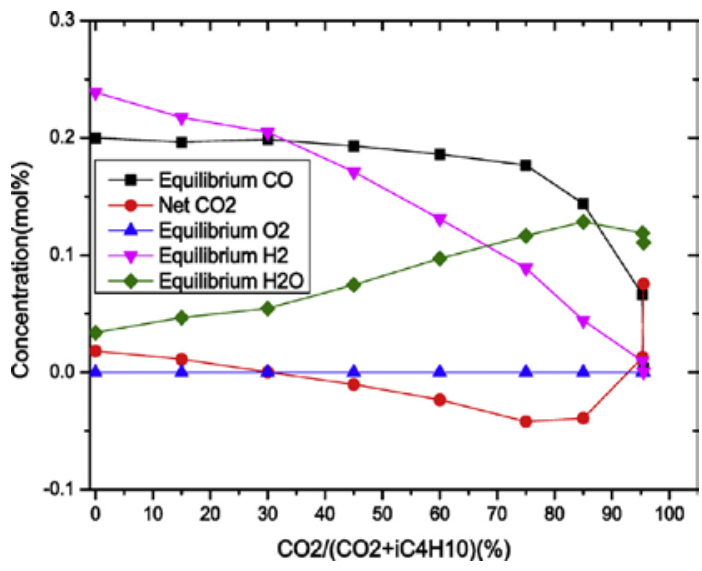

Fig. 4. Concentration of combustion products with different dilution ratio for isobutane at UFL. 


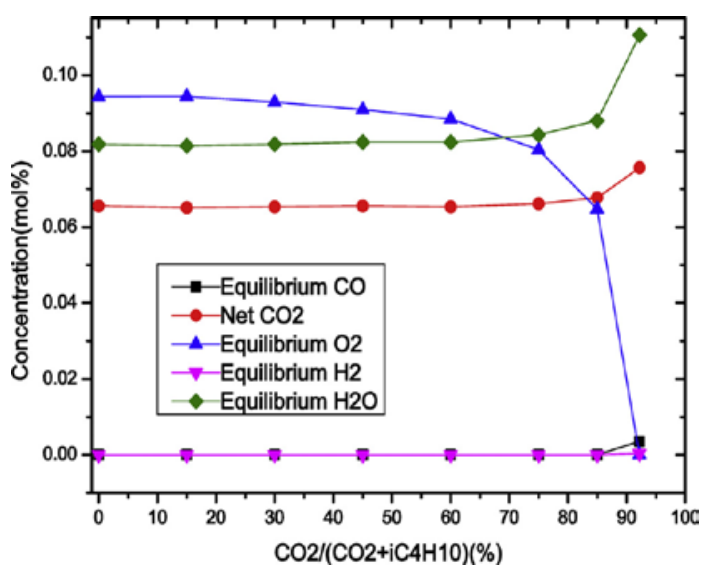

Fig. 5. Concentration of combustion products with different dilution ratio for isobutane at LFL.

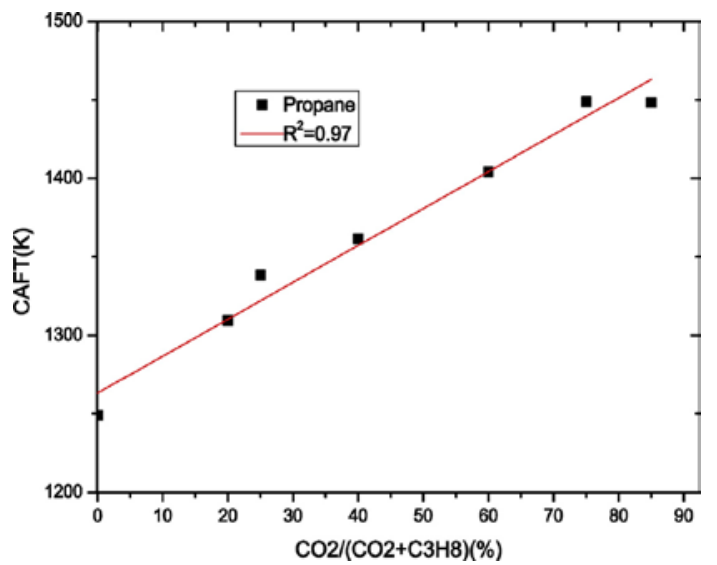

Fig. 6. Relationship between CAFT and dilution ratio for propane at UFL, except for the point of FIP.

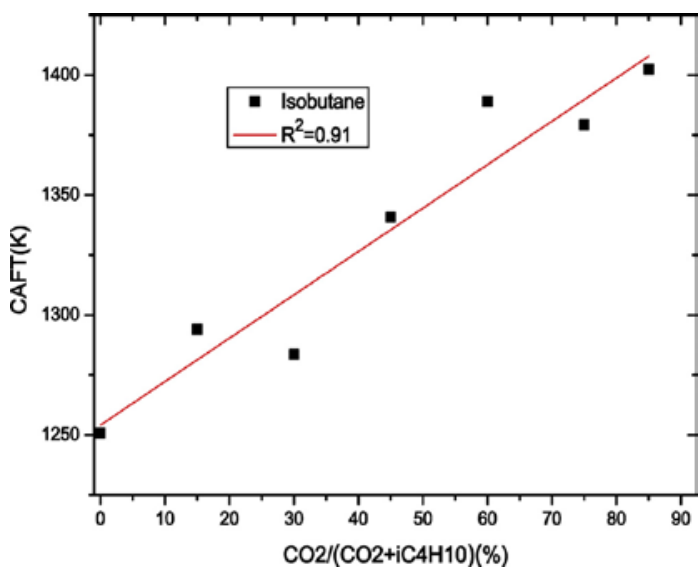

Fig. 7. Relationship between CAFT and dilution ratio for isobutane at UFL, except for the point of FIP.

\section{The VAFT model}

The adiabatic flame temperature calculated above at UFL highly depends on experimental data in literature. Fortunately there is a linear relationship between dilution ratio and CAFT that can solve the limitation by assuming a value of CAFT near fuel inertization point. Figs. $\mathbf{6}$ and $\mathbf{7}$ show that the CAFT at dilution ratio of $90 \%$ is in a narrow temperature range about $1400 \mathrm{~K}$. Thus, CAFT of 1400 $\mathrm{K}$ is adopted to predict flammability limits of mixtures that are listed above. The linear relation 
between CAFT and dilution ratio at UFL is available when flammability limit of pure alkane is known. Models using the linear relationship between two points, one point at $0 \%$ dilution ratio and one point at $90 \%$ dilution ratio, are built and called VAFT model.

The VAFT model is established at an initial pressure and temperature of $1 \mathrm{~atm}$ and $298 \mathrm{~K}$. Building and application of the VAFT model involves a three-step procedure. The detailed procedure can refer to Ref [12].

\subsection{Upper flammability limit}

Combustion products of most hydrocarbons at LFL always are $\mathrm{H}_{2} \mathrm{O}$ and $\mathrm{CO}_{2}$ for sufficient oxygen to support complete combustion. But the prediction at UFL is totally different from that at LFL due to oxygen deficiency. Thus, it is difficult to precisely calculate combustion products. As pointed out in Refs. $[\mathbf{1 0 , 1 4 , 1 7 ] , ~ t h e ~ c h e m i c a l ~ k i n e t i c s ~ h a s ~ i m p o r t a n t ~ i n f l u e n c e ~ o n ~ p r e d i c t i o n ~ a t ~ U F L . ~ T h u s , ~ i t ~ i s ~}$ difficult to precisely calculate combustion products without involving the chemical kinetics at UFL because there is not enough oxygen to oxidize $\mathrm{H}_{2}$ and $\mathrm{CO}$.

The following assumptions are employed when building the VAFT model to predict the UFL of alkane- $\mathrm{CO}_{2}$-air mixtures:

a) The combustion process at UFL occurs at a constant pressure which corresponds to the atmospheric pressure;

b) The VAFT calculated by linear relationship would be used in the model at UFL for alkane- $\mathrm{CO}_{2}$ air mixtures;

c) Oxygen is consumed according to the following three steps: Firstly, the alkane is oxidized to carbon monoxide and hydrogen; secondly depending on how much oxygen remains unutilized and using it to oxidize hydrogen to water vapor; and thirdly to oxidize sufficient carbon monoxide to carbon dioxide if there were still oxygen left.

The hypothesis (3) was first proposed by Lewis et al. [21]. and Bartok and Sarofim [22]. They considered that the $\mathrm{H}_{2}$ and $\mathrm{CO}$ was generated in quantity at UFL, which were not appreciably consumed until the entire hydrocarbon species have disappeared. That was because the active radicals such as $\mathrm{O}, \mathrm{H}, \mathrm{OH}$ were more inclined to react with hydrocarbon rather than $\mathrm{H}_{2}$ and $\mathrm{CO}$. The elementary reaction producing water $\mathrm{H}_{2} \mathrm{O}$ is easier to take place than that of $\mathrm{CO}_{2}$. Shu [12] proposed a FAFT model to calculate UFL firstly using the simple chemical kinetics.

According to the researches by $[\mathbf{6 , 1 4}]$, solving the energy balance equation that is composed of the heat absorption and release is objective of critical flame temperature theory. Mashuga [6] considered that if the values of the heat absorption and release were determined perfectly, the flammability limits calculated in model should be accuracy. Kinetics largely determines the heat release at UFL [12]. The heat absorption is affected by CAFT. The heat absorption and heat release can be calculated exactly at LFL due to the constant combustion products for complete combustion. The combustion products change from $\mathrm{CO}$ and $\mathrm{H}_{2}$ to $\mathrm{CO}, \mathrm{H}_{2} \mathrm{O}$ and $\mathrm{CO}_{2}$ with the $y$ increasing at UFL. The CAFT of different products is different. If the FAFT were used in model, the heat absorption calculated should be not the exact value. Thus, the VAFT and kinetics have equal significance for predicting UFL. This paper tries to use the VAFT to interpret heat absorption. The effectiveness of the hypothesis (b) about VAFT is validated in Section 2. Therefore, attempts are made to investigate whether the VAFT model could exactly predict UFL.

With energy balance and the reaction hypothesis, all of the parameters could be figured out. It is easy to obtain Eq. (1) by formula derivation. Ref [12]. can be referred to for the specific procedure. 


$$
\begin{aligned}
& \alpha_{1} H_{C O}^{0}+\alpha_{2} H_{C O_{2}}^{0}+\alpha_{3} H_{H_{2} O}^{0}+\alpha_{4} H_{H_{2}}^{0}+\alpha_{5} H_{N_{2}}^{0}+\frac{y \times U}{1-y} H_{D}^{0}+\Delta H_{C}^{*} \rightarrow \\
& \alpha_{1} H_{C O}^{a d}+\alpha_{2} H_{C O_{2}}^{a d}+\alpha_{3} H_{H_{2} O}^{a d}+\alpha_{4} H_{H_{2}}^{a d}+\alpha_{5} H_{N_{2}}^{a d}+\frac{y \times U}{1-y} H_{D}^{a d}
\end{aligned}
$$

The superscripts ' 0 ' and 'ad' refer to the initial temperature (298 K) and VAFT, respectively.

$H_{C O}^{0}=$ Enthalpy $($ Carbonmonoxide $, T=298 K, P=1 \mathrm{~atm})$

$H_{C O}^{a d}=$ Enthalpy $\left(\right.$ Carbonmonoxide,$T_{a d}=$ Function $\left.(y), P=1 \mathrm{~atm}\right)$

The linear relationship between CAFT and y, dilution ratio, can be used to calculate $T_{a d}$ in Eq. (3) when the value of $y$ is given. Values of enthalpy of reactants and products in Eq. (1) can be calculated directly by programs written by EES (Engineering Equation Solver). Thus, the UFL in the VAFT model for alkane$\mathrm{CO}_{2}$-air mixtures will be obtained by solving Eq. (1) in program.

\subsection{Fuel inertization point}

In preceding paper [5], fuel inertization point (FIP) is defined as the point on the envelope of flammable region in the triangular system of fuel-air-diluent which defines the maximum ratio of fuel to diluent concentration that never gives flammable mixtures whatever amount of air is added to or subtracted from the mixture. The UFL and LFL are equivalent when the mixture is in the FIP composition. Mixtures at fuel inertization point are as a rule fuel-rich for isobutane and propane. Thus, the model that is used to estimate the UFL would be applied for predicting the compositions at fuel inertization point. Just as is shown in Table.2, The CAFT at the point near FIP has higher value than any point on the envelope of flammable region because carbon dioxide generated rapidly according to Figs. 2 and 4. Hence, the higher CAFT would be chosen to determine the compositions at FIP, instead of the temperature determined by linear relation between CAFT and $y$.

It is generally known that flammability zones of alkane- $\mathrm{CO} 2$ mixture are very rare. In order to increase persuasion of the VAFT model, flammability limits of $n$-butane- $\mathrm{CO}_{2}$ and isopentane- $\mathrm{CO}_{2}$ mixtures would be measured to examine the validity of the models.

\subsection{Experimental method}

The experimental setup basically follows that of ASTM E681-09, which is revised version of ASTM E681-94. A schematic diagram of the experimental apparatus used to measure the flammability limits is shown in Fig. 8. The experimental setup is divided into two big systems, gas distribution system and explosion system, which consist of assembly units and subsystems such as valves and temperature control system. For the explosion system, the apparatus employs a spherical pressure-resistant flask with a volume of $12 \mathrm{~L}$. The vessel is enclosed in an air-bath kept at $30^{\circ} \mathrm{C}$. The ignition sparks for premixed gases are produced by a $15 \mathrm{KV}$ spark generator cross two tungsten electrodes that were set $(0.64 \mathrm{~cm})$ apart and located one third the diameter of the flask from the bottom of the flask. The spark duration is $0.4 \mathrm{~s}$ during which ignition energy of approximately $10 \mathrm{~J}$ is generated. The gas distribution system is mainly composed of two vacuum pumps, solenoid valves (V1-V8) and the pressure control subsystem. The gases mixtures are prepared in the reactor using partial pressure methodology. The hydrocarbon slowly comes into the flask first by opening $\mathrm{V} 1$, and then carbon dioxide. Finally introduce air into vessel, slowly raising the pressure to atmospheric pressure. Recording the amount of each component actually enters in vessel in each experiment. The mixture is determined to be flammable using a visual criterion. Purities of $n$-butane, propane, isopentane and carbon dioxide are $99.9 \%$. 


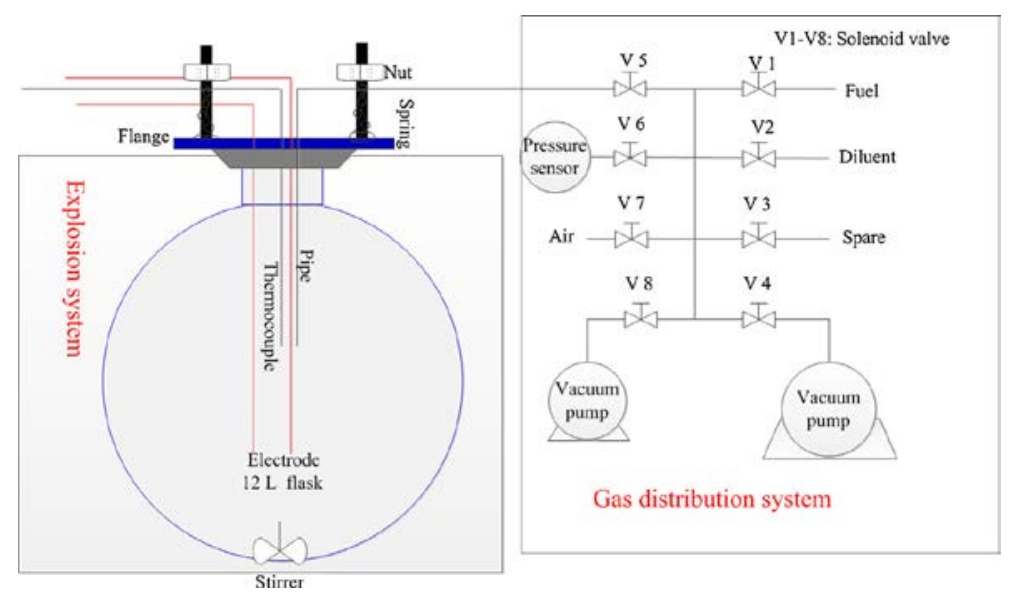

Fig. 8. Schematic diagram of flammability limits test system.

\section{Results and discussions}

In this section, the effectiveness of VAFT model for evaluation of the flammability limits of alkane- $\mathrm{CO}_{2}$-air mixtures would be examined by comparing with the existing experimental data $[\mathbf{1 9 , 2 0}]$ and observed values measured in this study.

\subsection{Flammable zone predictions for isobutane- $\mathrm{CO}_{2}$ and propane- $\mathrm{CO}_{2}$}

In order to provide explicit representation of the evaluated results, contrasts between the estimated results in former study, the estimated results in present study and the experimental results in Refs. $[\mathbf{1 9}, \mathbf{2 0}]$ are shown in Figs. 9 and 10. As is shown in Figs. 9 and 10, Cal 1 is the prediction profile in present study and Cal 2 is the prediction profile in former Ref. [12]. Furthermore, the flammability envelope of the experimental results in Refs. $[\mathbf{1 9 , 2 0}]$ is surrounded mostly by the profile of Cal 1 except that dilution ratio is close to 0.3 . The prediction profile of Cal 1 is closer to the experimental results than the profile of Cal 2, which means that hypothesis (b) is more appropriate comparing with the FAFT model. One possible reason for the difference between Cal 1 and observed results is that the estimated results were calculated at an initial temperature of $298 \mathrm{~K}$, while the experimental data was obtained at an initial temperature of $308 \mathrm{~K}$ which may lead to smaller values of UFL in experiment. The differences between the predicted results and experimental data will be illustrated elaborately in next subsections.

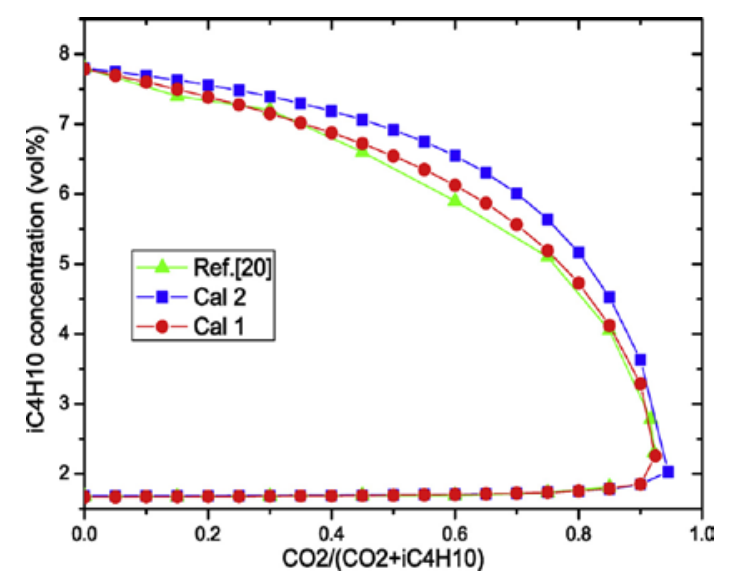

Fig. 9. Comparison between the predicted flammable zones ( $\mathrm{Cal} 1$ and $\mathrm{Cal} 2$ ) and experimental result [20] of isobutane-air- $\mathrm{CO}_{2}$ mixtures. 


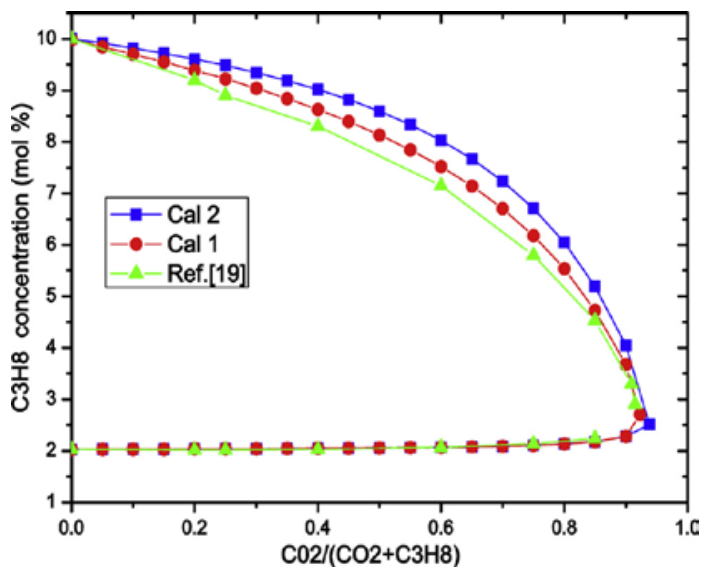

Fig. 10. Comparison between the predicted flammable zones (Cal 1 and $\mathrm{Cal} 2$ ) and experimental result [19] of propane-air- $\mathrm{CO}_{2}$ mixtures.

\subsubsection{Upper flammability limit}

Table 3 exactly demonstrates Cal 1, Cal 2, RD1, RD2 and observed results. RD1 and RD2 are the relative differences between predicted results ( $\mathrm{Cal} 1$ and $\mathrm{Cal} 2$ ) and observed values. Values of RD1 in present study are less than the values of RD2 in Ref. [12]. The average relative differences between the estimated values ( $\mathrm{Cal} 1$ ) and observed values, except for the results at fuel inertization point, are $2.08 \%, 3.51 \%$ for isobutane and propane, respectively; while those for the estimated values (Cal 2) and observed values are $7.79 \%, 9.64 \%$ for isobutane and propane, respectively. The only difference between present study and Ref. [12] is that a VAFT is used in present study while a FAFT is used in former study. The reason for the increase of CAFT at UFL may be related to reaction temperature of the elementary reaction discussed in Section 2. The results hint that the VAFT hypothesis introduced for the prediction of UFL is suitable comparing with the constant one adopted in former study.

Table 3. Comparison between the estimated results and observed results in Refs. $[\mathbf{1 9 , 2 0}]$ at UFL.

\begin{tabular}{lllllll}
\hline Fuel & $\mathrm{y}^{\mathrm{a}}$ & Obs $^{\mathrm{b}}\left(\right.$ vol\%) $^{2}$ & Cal 1(vol\%) & Cal 2(vol\%) & RD1(\%) & RD2(\%) \\
\hline iC4H10 & 0 & 7.8 & 7.8 & 7.8 & 0.00 & 0.00 \\
& 0.15 & 7.4 & 7.5 & 7.63 & 1.35 & 3.11 \\
& 0.3 & 7.2 & 7.15 & 7.39 & 0.69 & 2.64 \\
& 0.45 & 6.6 & 6.72 & 7.06 & 1.82 & 6.97 \\
& 0.6 & 5.9 & 6.13 & 6.54 & 3.90 & 10.85 \\
& 0.75 & 5.1 & 5.19 & 5.64 & 1.76 & 10.59 \\
& 0.85 & 4.05 & 4.12 & 4.52 & 1.73 & 11.60 \\
& 0.917 & 2.78 & 2.93 & 3.24 & 5.40 & 16.55 \\
C3H8 & 0 & 10 & 10 & 10 & 0.00 & 0.00 \\
& 0.2 & 9.2 & 9.38 & 9.6 & 1.96 & 4.35 \\
& 0.25 & 8.9 & 9.21 & 9.48 & 3.48 & 6.52 \\
& 0.4 & 8.3 & 8.61 & 9.01 & 3.73 & 8.55 \\
& 0.6 & 7.15 & 7.5 & 8.03 & 4.90 & 12.31 \\
& 0.75 & 5.8 & 6.15 & 6.71 & 6.03 & 15.69 \\
& 0.85 & 4.53 & 4.7 & 5.19 & 3.75 & 14.57 \\
& 0.909 & 3.3 & 3.44 & 3.8 & 4.24 & 15.15 \\
\hline
\end{tabular}

a $\mathrm{y}$ is dilution ratio.

b Observed value of UFL in Refs. [19,20].

\subsubsection{Fuel inertization point}


From Table 4, the relative differences (RD1) in present study are less than the relative differences (RD2) in the former study, whether for the molar fraction of carbon dioxide or for the concentration of alkanes at fuel inertization point. Results of relative differences in present study verify the effectiveness of the hypothesis (b) employed in model. For the molar faction of carbon dioxide at fuel inertization point, the relative differences between the Cal 1 and observed results are $0.33 \%$ and $0.87 \%$ for the isobutane and propane, respectively. However, for the concentration of alkanes at fuel inertization point, the corresponding relative differences are $1.74 \%$ and $6.55 \%$. Relatively speaking, the results are comparatively desirable. From the perspective of safety, the concentration of alkane is not as important as the molar fraction of diluent at fuel inertization point. After all, once the molar fraction of diluent exceeded the fuel inertization point, the alkane-diluent mixtures would become nonflammable compounds. Moreover, the prediction accuracy of the molar fraction of carbon dioxide is much higher than that of the concentration of alkane at fuel inertization point. Therefore, the VAFT model to calculate the parameters at fuel inertization point of alkane-air$\mathrm{CO}_{2}$ mixtures is appropriate.

Table 4. Comparison between the estimated results and experimental results in Refs. $[\mathbf{1 9 , 2 0}]$ at FIP.

\begin{tabular}{|c|c|c|c|c|c|c|c|c|c|c|}
\hline \multirow[t]{2}{*}{ Fuel } & \multicolumn{5}{|l|}{ Concentration } & \multicolumn{5}{|l|}{$y^{a}$} \\
\hline & Cal 1 (mol\%) & Cal $2(\mathrm{~mol} \%)$ & $\mathrm{Obs}^{\mathrm{b}}(\mathrm{mol} \%)$ & RD1 (\%) & $\mathrm{RD} 2(\%)$ & Cal 1 & Cal 2 & $\mathrm{Obs}^{\mathrm{b}}$ & RD1 (\%) & RD2 (\%) \\
\hline $\mathrm{iC}_{4} \mathrm{H}_{10}$ & 2.26 & 2.03 & 2.30 & 1.74 & 11.74 & 0.925 & 0.945 & 0.922 & 0.33 & 2.49 \\
\hline С $3 \mathrm{H} 8$ & 2.71 & 2.51 & 2.90 & 6.55 & 13.45 & 0.923 & 0.938 & 0.915 & 0.87 & 2.51 \\
\hline
\end{tabular}

\subsection{Flammable zone predictions for $n$-butane- $\mathrm{CO}_{2}$ and isopentane- $\mathrm{CO}_{2}$}

The upper flammability limit is determined by Eq. (4) in experiment. The uncertainty primarily comes from the step size namely $U_{1}-U_{2}$ at UFL according to the test standard of ASTM E681-09.

$U=\frac{U_{1}+U_{2}}{2}$

The UFL of propane were measured to verify the validity of experimental setup because the data of propane is more than that of $n$-butane. It is well known that the observed flammability limits depend highly on the vessels with which they are measured $[\mathbf{2 3}, \mathbf{2 5}]$. The flammability limits obtained in $12 \mathrm{~L}$ flask are closer to the true limits in actual environment than the flammability limits measured in the vertical glass tube based on the researches in Kondo [25] and Zlochower [23]. Considering the uncertainties and device dependence of flammability limit, the UFL of propane obtained here is reasonable. Thus, the validity of experimental setup is confirmed by comparing the data measured in different methods in Table 5.

Table 5. Comparing the flammability limits of propane measured with some data available in Refs. $[19,23,24]$.

\begin{tabular}{llll}
\hline UFL of propane(vol\%) & Vessels & Explosion criterion & Refences \\
\hline 10.09 & Vertical glass cylinder & Visual criterion & Measured by Zhao [23] \\
10 & 12 L glass flask & Visual criterion & Measured by Kondo [19] \\
9.8 & 120 L glass flask & Pressure criterion & Measured by Zlochower [24] \\
$9.85 \pm 0.3$ & 12 L glass flask & Visual criterion & This research \\
\hline
\end{tabular}

As shown in Figs. 11 and 12, flammable zone calculated by VAFT model is more close to flammable zone measured than flammability zone calculated by previous model. The quantitative analysis in Table 6 could exactly describe the deviation. The average relative differences between the estimated values ( $\mathrm{Cal} 1$ ) and observed values, except for the results at fuel inertization point, are $2.69 \%$ and $1.91 \%$ for $n$-butane and isopentane, respectively; while those for the estimated values (Cal 2) and observed values are $10.24 \%$ and $11.93 \%$. A good agreement is shown between observed results and 
results estimated by VAFT model. In general, the comparative results between Cal 1, Cal 2 and observed values in Figs. 9-12 show VAFT model are better than previous model.

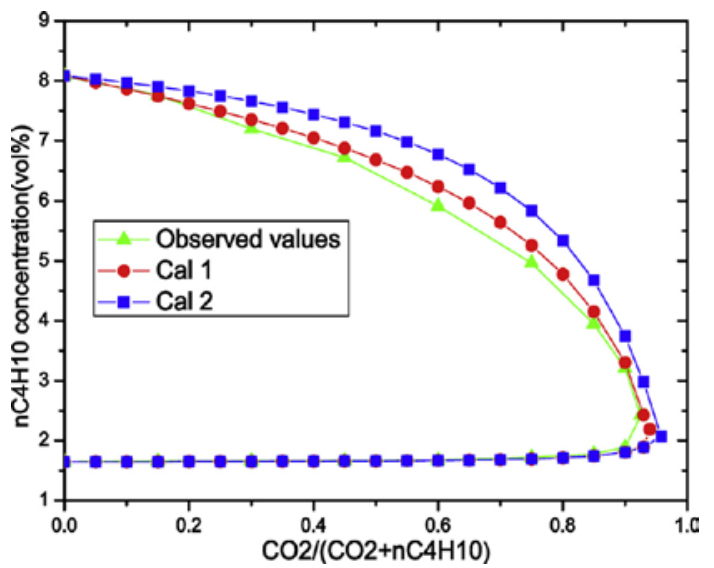

Fig. 11. Comparison between the predicted flammable zones and observed values of $n$-butane-air$\mathrm{CO}_{2}$ mixture.

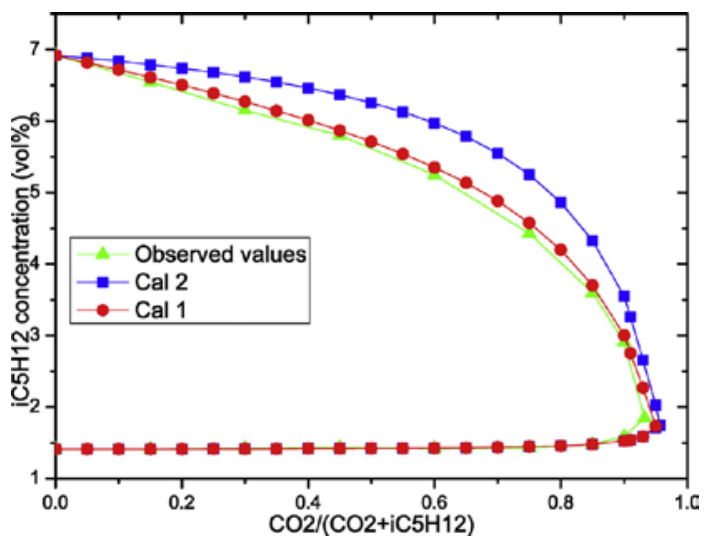

Fig. 12. Comparison between the predicted flammable zones and observed values of isopentane-air$\mathrm{CO}_{2}$ mixture.

Table 6. Comparison between the estimated results and observed results measured at UFL for $n$ butane-air- $\mathrm{CO}_{2}$ and isopentane- $\mathrm{CO}_{2}$ mixtures.

\begin{tabular}{|c|c|c|c|c|c|c|c|}
\hline fuel & $y^{n}$ & $\mathrm{UFL}^{\mathrm{b}}$ (vol\%) & $\operatorname{LFL}^{\mathrm{b}}\left(\mathrm{vol}^{\prime} \%\right)$ & Cal 1(vol\%) & Cal 2(vol\%) & RD1(\%) & $\mathrm{RD} 2(\%)$ \\
\hline \multirow[t]{11}{*}{$\mathrm{n}-\mathrm{C} 4 \mathrm{H} 10$} & 0 & $8.08(0.3)$ & $1.647(0.015)$ & 8.08 & 8.08 & 0 & 0 \\
\hline & 0.15 & $7.76(0.3)$ & $1.656(0.015)$ & 7.74 & 7.83 & 0.26 & 0.9 \\
\hline & 0.3 & $7.2(0.2)$ & $1.66(0.015)$ & 7.35 & 7.66 & 2.08 & 6.39 \\
\hline & 0.45 & $6.72(0.2)$ & $1.664(0.015)$ & 6.87 & 7.31 & 2.23 & 8.78 \\
\hline & 0.6 & $5.96(0.15)$ & $1.668(0.015)$ & 6.19 & 6.77 & 3.86 & 13.59 \\
\hline & 0.75 & $4.96(0.15)$ & $1.721(0.02)$ & 5.23 & 5.83 & 5.44 & 17.54 \\
\hline & 0.85 & $3.95(0.1)$ & $1.779(0.025)$ & 4.14 & 4.67 & 4.81 & 18.23 \\
\hline & 0.9 & $3.21(0.1)$ & $1.889(0.04)$ & 3.3 & 3.74 & 2.8 & 16.51 \\
\hline & 0.925 & 2.422 & $2.422(0.08)$ & & & & \\
\hline & 0.94 & & & 2.189 & & & \\
\hline & 0.958 & & & & 2.074 & & \\
\hline \multirow[t]{11}{*}{ iC5H12 } & 0 & $6.92(0.3)$ & $1.41(0.015)$ & 6.92 & 6.92 & 0.00 & 0.00 \\
\hline & 0.15 & $6.55(0.3)$ & $1.41(0.015)$ & 6.61 & 6.79 & 0.92 & 3.66 \\
\hline & 0.3 & $6.15(0.2)$ & $1.43(0.015)$ & 6.27 & 6.62 & 1.95 & 7.64 \\
\hline & 0.45 & $5.80(0.2)$ & $1.43(0.015)$ & 5.87 & 6.36 & 1.21 & 9.66 \\
\hline & 0.6 & $5.25(0.15)$ & $1.42(0.015)$ & 5.35 & 5.97 & 1.90 & 13.71 \\
\hline & 0.75 & $4.43(0.15)$ & $1.43(0.02)$ & 4.58 & 5.25 & 3.39 & 18.51 \\
\hline & 0.85 & $3.60(0.1)$ & $1.48(0.025)$ & 3.71 & 4.33 & 2.78 & 20.28 \\
\hline & 0.9 & $2.91(0.1)$ & $1.59(0.04)$ & 3 & 3.5 & 3.09 & 21.99 \\
\hline & 0.9324 & 1.85 & $1.85(0.08)$ & & & & \\
\hline & 0.95 & & & 1.73 & & & \\
\hline & 0.96 & & & & 1.74 & & \\
\hline
\end{tabular}

a $y$ is dilution ratio

Observed values measured in this study and numbers in parentheses are experimental uncertainties. 


\section{Conclusion}

The heat absorption greatly depends on the adiabatic flame temperature. Thus, the VAFT used in this paper and kinetics adopted in our previous paper have equal significance for predicting UFL. In this have been proposed. The validity and predictive ability of the VAFT model have been examined by comparing the two groups of estimated results that are derived through calculation with the experimental values. According to the investigation, following important conclusions are drawn:

(1) Through calculation of adiabatic flame temperature, we found and presented the linear correlation between dilution ratio and CAFT, which could be used in model to improve predicting accuracy.

(2) We presented a new model based on VAFT. Using this model, we predicted flammable zones of three alkane-CO2 mixtures. The average relative differences between results of the VAFT model and experimental ones, except for results at fuel inertization point, are $2.08 \%, 3.51 \%$, $2.69 \%$ and $1.91 \%$ for isobutane, propane, $\mathrm{n}$-butane and isopentane, respectively.

(3) The VAFT model can precisely provide safe prediction for the predicted flammable zones of mixtures just contain the flammable zone measured, which means the model has realistic worth in practical application.

\section{Acknowledgements}

This work was supported by a grant from the National Natural Science Foundation of China (No. 51676133).

\section{References}

[1] M.A. Siddiqi, B. Atakan, Alkanes as fluids in Rankine cycles in comparison to water, benzene and toluene, Energy, 45 (2012), pp. 256-263

[2] G. Shu, X. Li, H. Tian, X. Liang, H. Wei, X. Wang, Alkanes as working fluids for high-temperature exhaust heat recovery of diesel engine using organic Rankine cycle, Appl. Energ., 119 (2014), pp. 204217

[3] C.C. Chen, T.C. Wang, H.J. Liaw, H.C. Chen, Nitrogen dilution effect on the flammability limits for hydrocarbons, J. Hazard. Mater., 166 (2009), pp. 880-890

[4] P. Garg, P. Kumar, K. Srinivasan, P. Dutta, Evaluation of carbon dioxide blends with isopentane and propane as working fluids for organic Rankine cycles, Appl. Therm. Eng., 52 (2013), pp. 439-448

[5] S. Kondo, K. Takizawa, A. Takahashi, K. Tokuhashi, Extended Le Chatelier's formula and nitrogen dilution effect on the flammability limits, Fire Saf. J., 41 (2006), pp. 406-417

[6] T.G. Ma, A thermal theory for estimating the flammability limits of a mixture, Fire Saf. J., 46 (2011), pp. 558-567

[7] D.M. Himmelblau, J.B. Riggs, Basic Principles and Calculations in Chemical Engineering, Prentice Hall (2004)

[8] C.V. Mashuga, D.A. Crowl, Flammability zone prediction using calculated adiabatic flame temperatures, Process Saf. Prog., 18 (1999), pp. 127-134 
[9] J.G. Hansel, J.W. Mitchell, H.C. Klotz, Predicting and controlling flammability of multiple fuel and multiple inert mixtures, Plant/Oper. Prog., 11 (1992), pp. 213-217

[10] M. Vidal, W. Wong, W.J. Rogers, M.S. Mannan, Evaluation of lower flammability limits of fuelair-diluent mixtures using calculated adiabatic flame temperatures, J. Hazard. Mater., 130 (2006), pp. 21-27

[11] C.C. Chen, H.J. Liaw, T.C. Wang, C.Y. Lin, Carbon dioxide dilution effect on flammability limits for hydrocarbons, J. Hazard. Mater., 163 (2009), pp. 795-803

[12] G. Shu, B. Long, H. Tian, Flame temperature theory-based model for evaluation of the flammable zones of hydrocarbon-air-CO2 mixtures, J. Hazard. Mater., 294 (2015), pp. 137-144

[13] G. Shu, B. Long, H. Tian, Evaluating upper flammability limit of low hydrocarbon diluted with an inert gas using threshold temperature, Chem. Eng. Sci., 138 (2015), pp. 810-813

[14] X. Hu, Q. Yu, N. Sun, Experimental study of flammability limits of oxy-methane mixture and calculation based on thermal theory, Int. J. Hydrogen Energy, 39 (2014), pp. 9527-9533

[15] M. Palucis, T. Glowienka, V.V. Brunt, Prediction of flammability speciation for the lower alkanes, carboxylic acids, and esters, Process Safety Progress, 26 (2007), pp. 4-9

[16] D. Razus, M. Molnarne, Limiting oxygen concentration evaluation in flammable gaseous mixtures by means of calculated adiabatic flame temperatures, Chem. Eng. Process. Process Intensif., 43 (2004), pp. $775-784$

[17] Y.N. Shebeko, W. Fan, I.A. Bolodian, V.Y. Navzenya, An analytical evaluation of flammability limits of gaseous mixtures of combustible-oxidizer-diluent, Fire Saf. J., 37 (2002), pp. 549-568

[18] G.A. Melhem, A detailed method for estimating mixture flammability limits using chemical equilibrium, Process Safety Prog., 16 (1997), pp. 203-218

[19] S. Kondo, K. Takizawa, A. Takahashi, K. Tokuhashi, Extended Le Chatelier's formula for carbon dioxide dilution effect on flammability limits, J. Hazard. Mater., 138 (2006), pp. 1-8

[20] S. Kondo, K. Takizawa, A. Takahashi, K. Tokuhashi, A. Sekiya, Flammability limits of isobutane and its mixtures with various gases, J. Hazard. Mater., 148 (2007), pp. 640-647

[21] B. Lewis, G. von Elbe, Combustion, Flames and Explosions of Gases, (third ed.), Academic Press Inc., New York (1987)

[22] W. Bartok, A.F. Sarofim, Fossil Fuel Combustion, J. Wiley \& Sons, NewYork (1991)

[23] F. Zhao, W.J. Rogers, M.S. Mannan, Experimental measurement and numerical analysis of binary hydrocarbon mixture flammability limits, Process Saf. Environ. Prot., 87 (2009), pp. 94-104

[24] I.A. Zlochower, G.M. Green, The limiting oxygen concentration and flammability limits of gases and gas mixtures, J. Loss Prev. Process Ind., 22 (2009), pp. 499-505

[25] A. Takahashi, Y. Urano, S. Kondo, Effect of vessel size and shape on experimental flammability limits of gases, J. Hazard. Mater., 105 (2003), pp. 27-37

indicates the relative difference between CAFT in Ref. [12] and CAFT in present. 
